\title{
Adherence Properties of Acrylic Bone Cement to Alumina Ceramics Designed for Clinical Applications
}

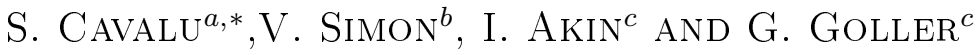 \\ ${ }^{a}$ University of Oradea, Faculty of Medicine and Pharmacy, P-ta 1 Decembrie 10, Oradea, Romania \\ ${ }^{b}$ Babes-Bolyai University, Faculty of Physics \& Institute of Interdisciplinary Research in \\ Bio-Nano-Sciences,Cluj-Napoca, Romania \\ ${ }^{c}$ Istanbul Technical University, Metallurgical \& Materials Engineering Department, Istanbul, Turkey

\begin{abstract}
The aim of this study is to investigate the adherence properties of acrylic cement based on PMMA to alumina ceramics. These ceramics are suitable for orthopedic and dental applications, as bioinert components in prosthetic surgery. The surface of alumina specimens were subjected to a special treatment based on acid etched followed by two different fluoride treatments: $\mathrm{SnF}_{2}$ and $\mathrm{NaBF}_{4}$, respectively. The structural properties of $\mathrm{Al}_{2} \mathrm{O}_{3}$ specimens were investigated before any treatments by X-ray diffraction, Fourier transform infrared spectroscopy and scanning electron microscopy. The modification occurred after the chemical treatment was investigated by X-ray photoelectron spectroscopy. The adherence of commercial acrylic cement to both treated alumina specimens was evaluated by scanning electron microscopy upon transversal cutting of the specimens. The results demonstrated that $\mathrm{SnF}_{2}$ is more favorable with respect to adhesion of PMMA based orthopedic cements.
\end{abstract}

DOI: $10.12693 /$ APhysPolA.125.603

PACS: $87.85 . j f$

\section{Introduction}

Ceramics have a great potential in the biomedical field, thanks to their biocompatibility, strength, and wear resistance. Alumina exhibits excellent hardness and wear properties; fracture toughness values are lower than those of the metals used in orthopedic surgery. Its outstanding biocompatibility and excellent tribological properties allow alumina ceramics to be widely used in total joint prosthesis. However, it is a brittle material, with low resistance to the propagation of cracks [1,2]. On the other hand, the surfaces modification and postsynthesis treatment also influence the performances of the bioceramics designed to dental and orthopedic applications $[3,4]$. It was demonstrated that the administration of complex fluorides as compared with $\mathrm{NaF}$ suggests the possibility of using them as effective agents in dental caries prevention in human populations [5]. For example, stannous fluoride converts the calcium mineral apatite into fluoroapatite, which makes tooth enamel more resistant to bacteria generated acid attacks.

Bone cements are acrylic based resins that were first used for joint arthoplasty surgery in 1958. Their function is to fill the space between the prosthesis and the bone, thereby fixing the prosthesis in the place and acting as an interface between the bone and prosthesis allowing load to be transferred during activity. The bone cements are two component systems. The powder component comprises pre-polymerised polymethyl metacry-

*corresponding author; e-mail: scavalu@rdslink. ro late (PMMA), an initiator benzoyl peroxide and a radiopaque component. An important parameter that can help predict long-term behavior of the prostheses is the permanent displacement, or migration, of the implant relative to bone. This incidence of migration is one of the predominant causes of failure and is mainly due to micromotion, the lack of fixation stability at the bone-implant interface. There was demonstrated [6] the importance of material flexibility and its effects on stress shielding. Materials with a high flexibility tend to have less bone resorption and the stress level in bone is significantly lower. The mechanical environment of the host bone is altered by the implantation of a foreign material and consequently, bone remodeling occurs in order to adapt the bone structure to this new situation [7]. The aim of this study is to investigate the adherence properties of acrylic cement (based on PMMA) to alumina ceramics, suitable for orthopedic and dental applications, as bio-inert components in prosthetic surgery. Prior to the adherence investigation, the surface of alumina specimens were subjected to a special treatment based on acid etching followed by two different fluoride treatments: $\mathrm{SnF}_{2}$ and $\mathrm{NaBF}_{4}$, respectively.

\section{Experimental procedure}

$\mathrm{Al}_{2} \mathrm{O}_{3}$ (Baikowski grade SM8, an average particle size of $0.6 \mu \mathrm{m}$ ) powder was used as starting material for sintering alumina ceramic specimens using SPS apparatus (SPS-7.40 MK-VII, SPS Syntex Inc.) at $1350{ }^{\circ} \mathrm{C}$. The surface morphology details were investigated by scanning electron microscopy (SEM, JEOL JSM 7000F). The alumina specimens were subjected to an acid etched treatment by soaking the samples for $40 \mathrm{~min}$ in hydrochloric/sulfuric acid followed by different fluoride treatments, 
$\mathrm{SnF}_{2}$ and $\mathrm{NaBF}_{4}$, respectively. High purity stannous fluoride (tin(II) fluoride) and sodium tetrafluoroborate (Sigma Aldrich) were used to prepare saturated solutions $(0.4 \mathrm{~g} / \mathrm{mL}$ and $1 \mathrm{~g} / \mathrm{mL}$, respectively) for surface treatment of the specimens by conventional anodization during $2 \mathrm{~h}$ at $12 \mathrm{~V}$ [8]. Upon the anodization treatment, the specimens were ultrasonically treated for $90 \mathrm{~min}$ to remove the deposits, then air-dried. The modifications of samples surface upon acid etched and both fluoride treatment were investigated by X-ray photoelectron spectroscopy (XPS) measurements performed with SPECS PHOIBOS 150 MCD system equipped with monochromatic $\mathrm{Al} K_{\alpha}$ source $(250 \mathrm{~W}, h \nu=1486.64 \mathrm{eV})$ and $E_{\text {pass }}=50 \mathrm{eV}$, with a resolution of $1 \mathrm{eV} / \mathrm{step}$. The vacuum in the analysis chamber during the measurements was kept in the range $10^{-9}-10^{-10}$ mbar. All binding energies were referenced to the $\mathrm{C} 1 s$ peak arising from adventitious carbon at $284.6 \mathrm{eV}$. The peak areas combined with the appropriate sensitivity factors allowed to quantify the elemental composition at the surface. The depth of analysis was about $5 \mathrm{~nm}$. Commercial PMMA bone cement $\left(\mathrm{BIOLOS} 3^{\circledR}{ }^{\circledR}\right)$ was prepared according to the manufacturer instructions and then manually pressed on the surfaces of both treated alumina specimens. The adherence of the cement to alumina specimen surface was evaluated by SEM upon transversal cutting of the specimens with a diamond disc.

\section{Results and discussions}

The morphology of monolithic alumina sintered ceramic is presented in Fig. 1a showing the details of both large and small equiaxed grains $0.5-3 \mu \mathrm{m}$ in size and straight grain boundaries. Figure $1 \mathrm{~b}$ shows the $\mathrm{X}$-ray diffractions (XRD) of $\mathrm{Al}_{2} \mathrm{O}_{3}$ sintered at $1350{ }^{\circ} \mathrm{C}$, with characteristic peaks of $\alpha$-corundum (JCPDS: 71-1683). The reflection lines occurring from crystallographic planes related to $\alpha$-corundum are clearly marked at $2 \theta=25.6,35.2,37.9,43.4,57.5,61.3,66.4,68.2,76.9$, and $80.7^{\circ}$.

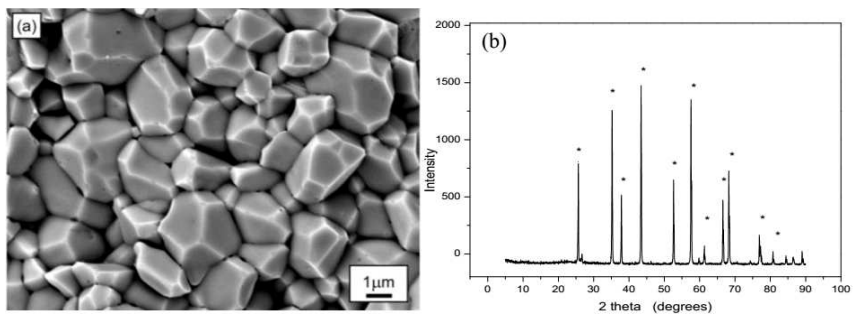

Fig. 1. (a) SEM micrograph recorded on the surface of $\mathrm{Al}_{2} \mathrm{O}_{3}$ ceramic sintered at $1350{ }^{\circ} \mathrm{C}$; (b) the corresponding XRD pattern.

The survey XPS spectra recorded on the specimens' surface before and after both fluoride treatments are presented comparatively in Fig. 2. The main photoelectron peaks in the spectra of the specimens before treatments are assigned to $\mathrm{Al} 2 s(117.9 \mathrm{eV}), \mathrm{Al} 2 p(74.3 \mathrm{eV})$,

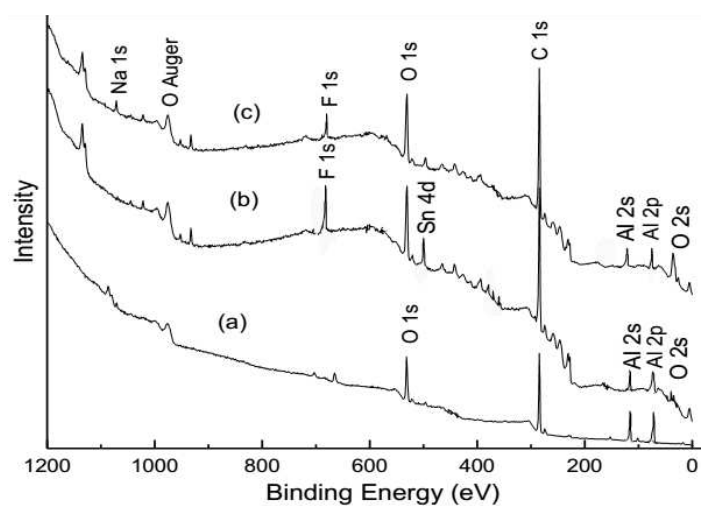

Fig. 2. XPS survey spectra of alumina ceramic reference specimen (a) and alumina ceramic treated with stannous fluoride (b), and sodium tetrafluoroborate (c), respectively.

O $1 s(531.8 \mathrm{eV})$. After $\mathrm{SnF}_{2}$ treatment, a strong peak at $487.1 \mathrm{eV}$ indicates the contribution of Sn $3 d$ electrons, while the presence of fluorine is proved by $\mathrm{F} 1 s$ photoelectrons peak at $685 \mathrm{eV}$. With respect to the $\mathrm{NaBF}_{4}$ treatment, the marker peaks in this case are $\mathrm{F} 1 \mathrm{~s}$ at $685.7 \mathrm{eV}$ and $\mathrm{Na} 1 \mathrm{~s}$ at $1072 \mathrm{eV}$, but this treatment shows a less effectiveness compared with $\mathrm{SnF}_{2}$. By comparing the results presented in Fig. $2 \mathrm{a}-\mathrm{c}$ and the atomic concentration of $\mathrm{Sn}, \mathrm{F}$, and $\mathrm{Na}$ on the surface of the specimens after fluoride treatment (Table) we can notice that alumina ceramic specimens present a high sensitivity to the $\mathrm{SnF}_{2}$ treatment. In some other previous studies, XPS has been successfully used to investigate the surface chemistry of the commercial alumina/zirconia implants, showing substantial differences from bulk [9]. For example, after different surface modification such as sandblasting or acid etching procedure, large differences in the XPS elemental composition were identified for the collar and threaded root of the commercial implants.

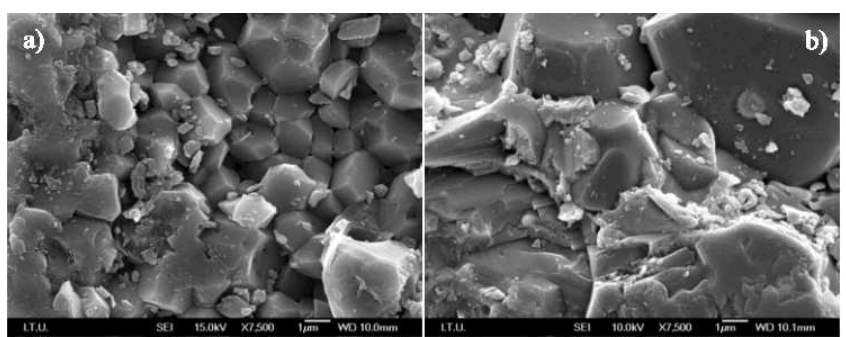

Fig. 3. The surface of alumina ceramics after treatment with different fluoride: (a) $\mathrm{SnF}_{2}$, (b) $\mathrm{NaBF}_{4}$.

The surface modification of both specimens (treated with $\mathrm{SnF}_{2}$ and $\mathrm{NaBF}_{4}$, respectively) was investigated by SEM and the details are presented in Fig. 3.

In order to evaluate the adherence properties of acrylic cement (PMMA) to alumina ceramic surface, the specimens treated with $\mathrm{SnF}_{2}$ and $\mathrm{NaBF}_{4}$, respectively, were covered with a thick layer of PMMA during the work- 
TABLE

Atomic concentration of Sn, F, and $\mathrm{Na}$ on the surface of the specimens after fluoride treatment, determined from XPS survey spectra.

\begin{tabular}{|c|c|c|c|c|}
\hline \multirow{3}{*}{ Specimen } & \multicolumn{4}{|c|}{ Elemental composition [at.\%] } \\
\hline & \multirow{2}{*}{ Sn } & \multicolumn{2}{|c|}{$\mathrm{F}$} & \multirow{2}{*}{$\mathrm{Na}$} \\
\hline & & $\mathrm{SnF}_{2}$ & $\mathrm{NaBF}_{4}$ & \\
\hline $\mathrm{Al}_{2} \mathrm{O}_{3}$ & 3.4 & 4.9 & 3.2 & 2.1 \\
\hline
\end{tabular}

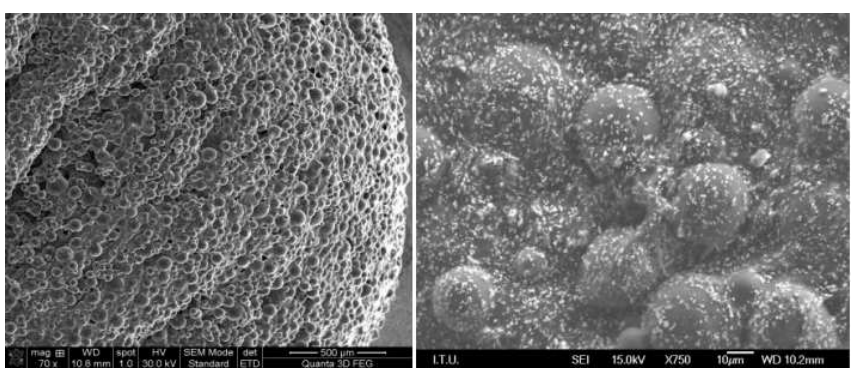

Fig. 4. SEM images recorded on the surface of PMMA-bone cement layer: (a) general view, (b) details with high magnification.

ing time of polymerization and then manually pressed for $15 \mathrm{~min}$. SEM images of the acrylic cement surface are recorded from the top view with different details and magnifications and presented in Fig. 4. The details of PMMA balls can be observed. After transversal cutting, the interface region between alumina ceramic and acrylic cement was investigated by SEM. The micrograph

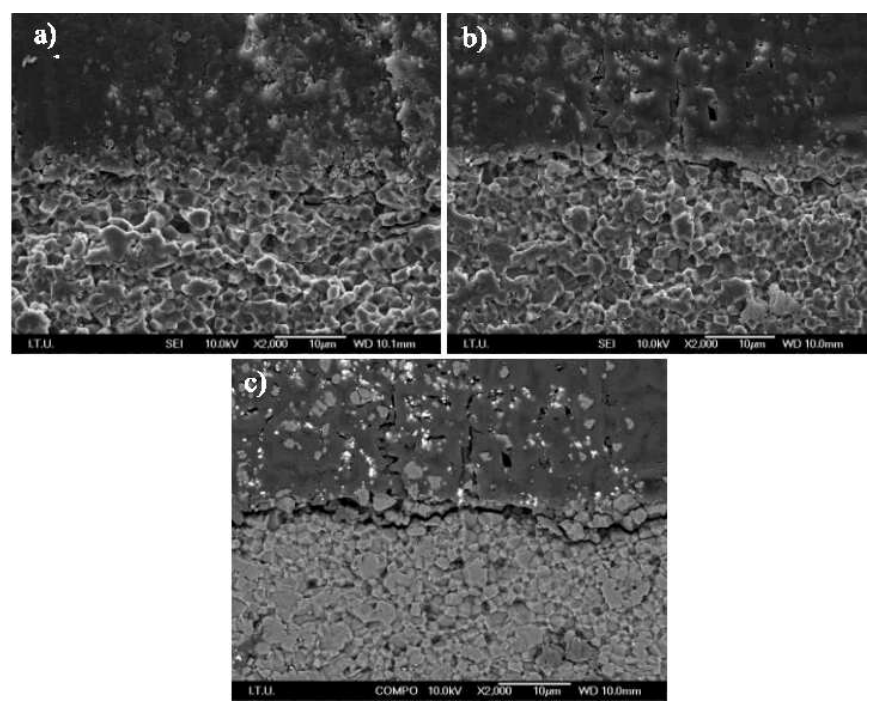

Fig. 5. Interface region between alumina ceramic and acrylic cement (transversal cut): (a) alumina specimen treated with $\mathrm{SnF}_{2}$, (b) alumina specimen treated with $\mathrm{NaBF}_{4}$, (c) the same image as (b) but recorded in backscattering mode in order to emphasize the bonding details. recorded on both specimens (with $\mathrm{SnF}_{4}$, and respectively, $\mathrm{NaBF}_{4}$ treatment) are presented in Fig. 4. The details of PMMA balls can be observed. After transversal cutting, the interface region between alumina ceramic and acrylic cement was investigated by SEM. The micrograph recorded on both specimens (with $\mathrm{SnF}_{4}$ respectively $\mathrm{NaBF}_{4}$ treatment) are presented in Fig. 5a-c. As revealed by the SEM details, the adherence of acrylic cement to alumina ceramic seems to be favored by the $\mathrm{SnF}_{2}$ treatment, as the interface shows a good bonding, without gaps or cracks within the cement layer.

\section{Conclusions}

The aim of this study was to evaluate the adherence properties of commercial acrylic bone cement to alumina ceramics after different fluoride-based treatments. The surface modifications occurred upon acid etched and $\mathrm{SnF}_{2} / \mathrm{NaBF}_{4}$ treatments were investigated by XPS and SEM, demonstrating that alumina ceramic specimens present a high sensitivity to the $\mathrm{SnF}_{2}$ treatment. The SEM micrographs recorded on the interface demonstrated that the adherence of acrylic cement to alumina ceramic seems to be favored by the $\mathrm{SnF}_{2}$ treatment.

\section{Acknowledgments}

This work was supported by the Romanian National Authority for Scientific Research UEFISCDI, project PNII-ID-PCE 2011-3-0441, contract 237/2011 and Bilateral Cooperation between Romania and Turkey 20122013.

\section{References}

[1] J. Chevalier, L. Gremillard, J. Eur. Ceram. Soc. 29 1245 (2009).

[2] J.A. D'Antonio, K. Sutton, J. Am. Acad. Orthop. Surg. 17, 63 (2009).

[3] I. Yondem, O. Inan, Int. J. Appl. Ceram. Technol. 8, 437 (2011).

[4] K. Duan, R. Wang, J. Mater. Chem. 16, 2309 (2006).

[5] F. Hattab, J. Dent. 17, 47 (1989).

[6] R. Huiskes, H. Weinans, B. Van Rietbergen, Clin. Orthop. Res. 274, 124 (1997).

[7] F.K. Chang, J.L. Perez, J.A. Davidson, J. Biomed. Mater. Res. 24, 873 (1990).

[8] S. Cavalu, F. Banica, V. Simon, I. Akin, G. Goller, Int. J. Appl. Ceram. Technol. (2013).

[9] S. Zenelis, A. Thomas, K. Syres, N. Silikas, G. Eliades, Dent. Mater. 26, 295 (2010). 